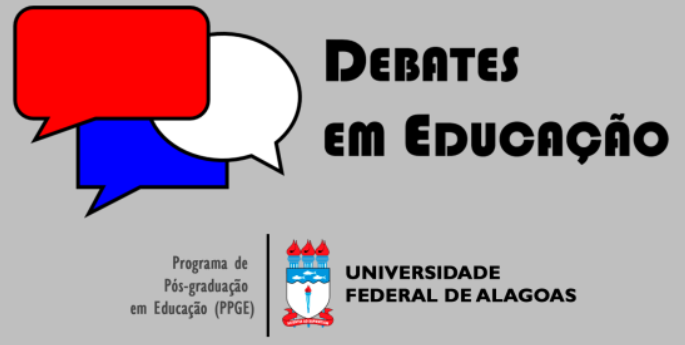

ISSN Eletrônico 2175-6600

Vol. 12 | Número Especial | 2020

Eliane Travensoli Parise Cruz

9 i

Universidade Estadual de Ponta Grossa (UEPG) elianeparise@gmail.com

Vera Lucia Martiniak

9 iD

Universidade Estadual de Ponta Grossa (UEPG) veramartiniak07@yahoo.com.br

\section{LEITURA E FORMAÇÃO DOCENTE: IMPLICAÇÕES PARA A CONSTRUÇÃO DO ALUNO LEITOR}

\section{RESUMO}

O texto apresenta uma análise dos resultados obtidos no teste de proficiência em leitura na ANA e da formação docente, bem como, informações sobre a elaboração da matriz de referência, das escalas de leitura a fim de verificar as possibilidades de comparabilidade dos resultados para construir um diagnóstico referente à formação do aluno leitor. Trata-se de pesquisa documental realizada a partir de dados levantados nos documentos oficiais do PNAIC sobre a elaboração da matriz de referência das escalas de leitura para mensurar os resultados alcançados. Contou com análises sobre o teste de leitura na ANA nas três edições, nos quatros níveis de leitura aplicados aos alunos do terceiro ano do Ensino Fundamental como também, o nível e formação docente. A pesquisa revelou que não basta avaliar o nível de leitura dos alunos, é preciso considerar a realidade das escolas brasileiras, as diferenças regionais, a cultura e o saber sistematizado.

Palavras-chave: Formação de Professores. Alfabetização. Leitura.

\section{READING AND TEACHING EDUCATION: IMPLICATIONS FOR THE CONSTRUCTION OF THE READING STUDENT}

\begin{abstract}
The text presents an analysis of the results obtained in the reading proficiency test at ANA and of the teacher education as well as information about the elaboration of the reference matrix, of the reading scales in order to verify the possibilities of comparability of the results to build a referring diagnosis regarding the training of the student reader. This is a documentary research carried out based on data collected in the official documents of the PNAIC on the elaboration of the reference matrix, of the reading scales to measure the results achieved. It had analyzes on the reading test at ANA in the three editions, in the four reading levels applied to students of the third year of Elementary School as well as the level and teacher training. The research revealed that it is not enough to assess the reading level of students, it is necessary to consider the reality of Brazilian schools, regional differences, culture and systematized knowledge.
\end{abstract}

Keywords: Teacher Education. Literacy. Reading.

Submetido em: 06/04/2020

Aceito em: 27/07/2020

Publicado em: 10/12/2020

do http://dx.doi.org/ 10.28998/2 I 75-6600.2020v I 2nEspp I 54- I 7 | 


\section{INTRODUÇÃO}

A educação assegura aos alunos o direito de aprendizagem da leitura e da escrita no processo de alfabetização. Para que essa aprendizagem ocorra, é necessário que o professor tenha clareza da importância da sua atuação a fim de proporcionar uma prática pedagógica que possibilite ao aluno desenvolver-se como leitor.

A preocupação com a formação continuada de professores tem sido um tema constante nos discursos e nas propostas de formulação de políticas educacionais, já que nas justificativas para a precariedade do ensino estão aquelas propagadas pelo governo que centralizam a problemática no interior da sala de aula e na figura do professor (FREITAS, 2000).

Essa precariedade diz respeito à fragilidade da formação de professores, que, muitas vezes, ocorre pela organização de cursos de curta duração com ênfase maior no aspecto prático-técnico em detrimento da formação de um professor culto, dotado de fundamentação teórica consistente que possibilite densidade a sua prática docente. (SAVIANI, 200I).

Geraldi (20|4) assevera ainda que os baixos índices de leitura de estudantes estão atrelados a uma alfabetização inicial de baixa qualidade, com base na concepção de leitura e escrita como decodificação e codificação.

De acordo com Cagliari (1997, p. I 49), "[...] a leitura é a realização do objetivo da escrita. Quem escreve, escreve para ser lido". Não se trata de aprender a ler para cumprir exigências oficiais, alcançar resultados satisfatórios em avaliações de larga escala, mas ler além do espaço escolar, como processo de transformação social.

A leitura é condição sine qua non ao processo de descoberta de novos sentidos, na construção do leitor experiente e da emancipação humana, pois ela fornece subsídios para que ele participe da realidade de forma consciente e, assim, exerça seu papel como sujeito participativo na sociedade.

A análise comparativa dos resultados da Avaliação Nacional de Alfabetização - ANA, da formação docente e os dos indicadores contextuais foi importante para verificar que a aprendizagem da leitura na alfabetização pode contribuir para o processo da construção do leitor crítico, ativo e participativo na sociedade já que, a escola tem como tarefa central, a socialização do saber historicamente produzido pela humanidade (DUARTE, 200I).

Neste sentido, pretende-se, aqui, apresentar as análises realizadas sobre os resultados obtidos no teste de proficiência em leitura na ANA e da formação docente bem como informações sobre a elaboração da matriz de referência, das escalas de leitura a fim de verificar as possibilidades de comparabilidade dos resultados para construir um diagnóstico referente à formação do aluno leitor. 


\section{COMPREENSÃO SOBRE ANA}

A ANA é destinada a unidades escolares e às crianças matriculadas no $3^{\circ}$ ano do ensino fundamental, com o objetivo de aferir os níveis de alfabetização e letramento em Língua Portuguesa (leitura e escrita) e alfabetização em Matemática. A ANA integra o Sistema de Avaliação da Educação Básica (Saeb), bem como é um dos eixos que compõe o Pacto Nacional pela alfabetização na Idade Certa, cujas metas obedecerão a três medidas principais, destacadas no art. $9^{\circ}$ da portaria 867/2012:

I - avaliação do nível de alfabetização, mediante a aplicação anual da Provinha Brasil aos estudantes das escolas participantes, pelas próprias redes de ensino, no início e no final do $2^{\circ}$ ano do ensino fundamental;

II - disponibilização pelo INEP, para as redes públicas, de sistema informatizado para coleta e tratamento dos resultados da Provinha Brasil;

III - análise amostral, pelo INEP, dos resultados registrados após a aplicação da Provinha Brasil, no final do $2^{\circ}$ ano;

IV - avaliação externa universal do nível de alfabetização ao final do $3^{\circ}$ ano do ensino fundamental, aplicada pelo INEP (BRASIL, 20 I2a).

O interesse pelo Ciclo de Alfabetização refere-se à atenção pelo período em que é considerado necessário, a fim que seja assegurado à criança o direito às aprendizagens básicas da apropriação da leitura e da escrita, bem como, ao desenvolvimento de outros saberes fundamentais das áreas e componentes curriculares obrigatórios.

São objetivos da ANA:

i) Avaliar o nível de alfabetização dos educandos no $3^{\circ}$ ano do ensino fundamental;

ii) Produzir indicadores sobre as condições de oferta de ensino;

iii) Concorrer para a melhoria da qualidade do ensino e redução das desigualdades, em consonância com as metas e políticas estabelecidas pelas diretrizes da educação nacional (BRASIL, 20I3).

A perspectiva de avaliação assumida pela ANA integra-se a um processo avaliativo que considera:

[...] a avaliação da aprendizagem dos estudantes, em que o professor tem um protagonismo central, mas há também a necessária avaliação da instituição como um todo, na qual o protagonismo é do coletivo dos profissionais que trabalham e conduzem um processo complexo de formação na escola, guiados por um projeto político-pedagógico coletivo. E, finalmente, há ainda a avaliação do sistema escolar, ou do conjunto das escolas de uma rede escolar, na qual a responsabilidade principal é do poder público. Esses três níveis de avaliação não são isolados e necessitam estar em regime de permanentes trocas, respeitados os protagonistas, de forma que se obtenha legitimidade técnica e política (BRASIL. MEC, 2007 (grifos no documento).

Vista, neste sentido, a proposta implica não somente avaliar o desempenho das crianças, mas abrange o contexto global dos processos avaliativos.

Segundo o Documento Básico da ANA (BRASIL, 20 I3, p. |4),

as matrizes da Avaliação Nacional da Alfabetização em Língua Portuguesa e Matemática foram elaboradas a partir das contribuições de diferentes pesquisadores e especialistas no campo da alfabetização e do letramento, de várias universidades, bem como de representantes de diversas 
instituições do governo e da sociedade civil, tais como Ministério da Educação (MEC), Conselho Nacional de Educação (CNE), União Nacional dos Dirigentes Municipais de Educação (Undime), Associação Nacional de Pós Graduação e Pesquisa em Educação (Anped), União Nacional dos Conselhos Municipais de Educação (UNCME), Conselho Nacional de Secretários de Educação (Consed), Secretarias de Educação, dentre outras.

Em se tratando da avaliação em Língua Portuguesa, a ANA trabalha com o pressuposto de que alfabetização e letramento têm especificidades diferentes e são interdependentes. Dentre os limites metodológicos e técnicos na construção de itens objetivos, de múltipla escolha, a ANA considera, para a leitura, o texto como produto e não como processo (BRASIL, 20 I3).

O Instituto Nacional de Estudos e Pesquisas Educacionais Anísio Teixeira - INEP, formula matrizes de referência para cada avaliação, as quais são construídas para aglutinar características que geram as informações sobre cada construto.

A matriz de Língua Portuguesa está organizada em dois eixos: o da Leitura e o da Escrita, abrangendo diferentes níveis da leitura e escrita de palavras até a leitura e escrita de textos, incluindo um conjunto de conhecimentos e habilidades linguísticas.

Tabela I - Matriz de referência

EIXO ESTRUTURANTE
HABILIDADE
HI. Ler palavras com estrutura silábica canônica
H2. Ler palavras com estrutura silábica não canônica
H3. Reconhecer a finalidade do texto
H4. Localizar informações explícitas em textos
H5. Compreender os sentidos de palavras e expressões em textos
H6. Realizar inferências a partir da leitura de textos verbais
H7. Realizar inferências a partir da leitura de textos que articulem a
linguagem verbal e não verbal
H8. Identificar o assunto de um texto
H9. Estabelecer relações entre partes de um texto marcadas por
elementos coesivos

Fonte: Brasil (20|5).

Na perspectiva de letramento, a alfabetização pressupõe a leitura de textos de diferentes gêneros, assim as práticas de letramento, incluindo a leitura, são amplas e diversificadas e ocorrem em diferentes contextos socioculturais, em situações específicas de uso. Em uma concepção discursiva da linguagem, a interação acontece por meio de textos verbais e não-verbais, com escolhas relacionadas aos contextos, aos interlocutores, às finalidades, aos usos e funcionamentos que os gêneros textuais assumem na sociedade (BRASIL, 20I3).

Segundo o INEP, a matriz foi produzida a partir de conhecimentos linguísticos passíveis de serem examinados com uma prova de avaliação em larga escala. Os limites metodológicos e técnicos relacionados à construção de itens objetivos, de múltipla escolha evidenciam que a ANA avalia determinados produtos da leitura próprios do letramento que se constrói na escola. 
Para mensurar o resultado foram estabelecidas escalas de proficiência, na composição dos níveis de leitura foram agrupadas as habilidades relacionadas àquele nível, a tabela 2 apresenta a escala de leitura:

Tabela 2 - Escala de leitura

\begin{tabular}{|c|c|}
\hline NIVEIS & DESCRIÇÃO \\
\hline Nível I (até 425 pontos) & $\begin{array}{l}\text { Neste nível, os estudantes provavelmente são capazes de: } \\
\text { - Ler palavras com estrutura silábica canônica, não canônica e } \\
\text { ainda que alternem sílabas canônicas e não canônicas }\end{array}$ \\
\hline Nível 2 (maior que 425 até 525 pontos) & $\begin{array}{l}\text { Além das habilidades descritas no nível anterior, os estudantes } \\
\text { provavelmente são capazes de: } \\
\text { - Localizar informações explícitas em textos curtos como } \\
\text { piada, parlenda, poema, quadrinho, fragmentos de narrativas } \\
\text { e de curiosidade científica; em textos de maior extensão, } \\
\text { quando a informação está localizada na primeira linha do } \\
\text { texto; } \\
\text { - Reconhecer a finalidade de texto como convite, cartaz, } \\
\text { receita, bilhete, anúncio com ou sem apoio de imagem; } \\
\text { - Identificar assunto de um cartaz apresentado em sua forma } \\
\text { original e ainda em textos cujo assunto pode ser identificado } \\
\text { no título ou na primeira linha; - Inferir sentido em piada e em } \\
\text { história em quadrinhos que articula linguagem verbal e não } \\
\text { verbal. }\end{array}$ \\
\hline Nível 3 (maior que 525 até 625 pontos) & $\begin{array}{l}\text { Além das habilidades descritas nos níveis anteriores, os } \\
\text { estudantes provavelmente são capazes de: } \\
\text { - Localizar informação explícita em textos de maior extensão } \\
\text { como fragmento de literatura infantil, lenda, cantiga folclórica } \\
\text { e poema, quando a informação está localizada no meio ou ao } \\
\text { final do texto; } \\
\text { - Identificar o referente de um pronome pessoal do caso reto } \\
\text { em textos como tirinha e poema narrativo; - Inferir relação } \\
\text { de causa e consequência em textos exclusivamente verbais - } \\
\text { piada, fábula, fragmentos de textos de literatura infantil e texto } \\
\text { de curiosidade científica - com base na progressão textual; e } \\
\text { em textos que articulam a linguagem verbal e não verbal - } \\
\text { tirinha; sentido em história em quadrinhos que articula } \\
\text { linguagem verbal e não verbal com vocabulário específico de } \\
\text { textos de divulgação científica ou que exige conhecimento } \\
\text { intertextual de narrativas infantis; o assunto de texto de } \\
\text { extensão média de divulgação científica para crianças, com } \\
\text { base nos elementos que aparecem no início do texto; o } \\
\text { significado de expressão de linguagem figurada em textos } \\
\text { como poema narrativo, fragmentos de literatura infantil, de } \\
\text { curiosidade científica e tirinha }\end{array}$ \\
\hline Nível 4 (maior que 625 pontos) & $\begin{array}{l}\text { Além das habilidades descritas nos níveis anteriores, os } \\
\text { estudantes provavelmente são capazes de: } \\
\text { - Reconhecer relação de tempo em texto verbal e os } \\
\text { participantes de um diálogo em uma entrevista ficcional; } \\
\text { - Identificar o referente de pronome possessivo em poema; } \\
\text { o referente de advérbio de lugar em reportagem; o referente } \\
\text { de expressão formada por pronome demonstrativo em } \\
\text { fragmento de texto de divulgação científica para o público } \\
\text { infantil; } \\
\text { - Inferir sentido em fragmento de conto; sentido de palavra } \\
\text { em fragmento de texto de literatura infantil; assunto em texto } \\
\text { de extensão média ou longa, considerando elementos que } \\
\text { aparecem ao longo do texto, em gêneros como divulgação } \\
\text { científica, curiosidade histórica para criança e biografia. }\end{array}$ \\
\hline
\end{tabular}

Fonte: INEP (20|5). 
Os testes destinados a aferir os níveis de alfabetização e desempenho em alfabetização e letramento em língua portuguesa e alfabetização em matemática foram compostos por 20 itens e mais 3 itens de produção escrita. Para a divulgação dos resultados, a partir de 2014, o INEP elaborou o Painel Educacional, que apresenta os dados consolidados, agregados por estado e município, divididos em: trajetória, contexto e aprendizagem.

No campo da Trajetória, há informações sobre a quantidade de matrículas nos anos iniciais, finais e médio, a média de estudantes por turmas, estudantes incluídos, matrículas em tempo integral, taxa de aprovação, reprovação, abandono e distorção idade-série.

No item Contexto, é possível consultar o indicador de nível socioeconômico, o indicador de complexidade da gestão escolar, o indicador de esforço docente, o indicador de adequação da formação docente, o indicador de regularidade docente e o indicador de desenvolvimento da Educação Básica.

E no quesito Aprendizagem, encontram-se os resultados da ANA - 2013, 2014 e 2016. São disponibilizadas informações sobre a participação de estudantes e escolas e a distribuição percentual dos estudantes por nível de proficiência em leitura, escrita e matemática.

A distribuição das proficiências dos participantes na escala permite estimar em termos quantitativos o desempenho das turmas, das escolas, das redes municipais, estaduais ou federais, bem como o desempenho nacional. A descrição dos níveis de proficiência oferece explicações sobre o que está sendo medido com o instrumento e a proficiência estimada, oferecendo uma descrição do desempenho naquele nível em que o estudante, turma, escola está alocada (BRASIL, 20 I3).

Um nível de proficiência agrupa um conjunto de habilidades comuns a um determinado grupo de alunos e é estruturado a partir dos resultados nos testes de desempenho. Embora isso não signifique que um estudante posicionado em um nível não tenha habilidades do nível subsequente, porém, no teste determinado, apresentou habilidades descritas em um dado nível. A escala permite verificar a interdependência entre operação cognitiva, objeto de conhecimento e contexto para a definição do referido nível.

Em relação aos níveis de leitura, no nível I consta a leitura de palavras a partir de imagens, assim os estudantes, situados neste nível, conseguem ler apenas palavras, desde que relacionadas a uma imagem.

No nível 2 estão os itens que exigem a leitura integral ou parcial de textos, cujos itens com assunto no título ou na frase inicial têm maior grau de acerto.

A habilidade de localização de informação explícita está dividida nos níveis 2, 3 e 4 da escala, reafirmando a ideia de que o contexto em que essa habilidade é exigida influencia na dificuldade para resposta. $\bigcirc$ nível de dificuldade para localização de informação explícita em textos nos itens alocados nos níveis 2 e 3, ocorre pela localização da informação no início, meio ou fim e pela forma como está disposta 
no texto, direta ou invertida, pela extensão dos textos e dificuldades de compreensão de textos mais complexos.

Já no nível 3, os alunos podem inferir sentido com base em elementos verbais e não-verbais em tirinhas, e, no nível 4, conseguem pressupor sentido em texto verbal. A identificação dos referentes pronominais surge apenas nos níveis 3 e 4.

A próxima seção apresenta uma análise comparativa dos resultados na ANA no teste em leitura e da formação docente, realizado nos anos de 2013, 2014 e 2016 no munícipio de Ponta Grossa, Paraná.

\section{A LEITURA COMO REFERÊNCIA NA ANA: UMA ANÁlise COMPARATIVA DOS RESULTADOS}

A avaliação de políticas e programas públicos vêm adquirindo relevância significativa como meio de mensurar o desempenho dos alunos, além de realizar a prestação de contas à sociedade, evidenciando às avaliações em larga escala no diagnóstico da qualidade da educação brasileira.

O PNAIC é o único programa de formação continuada de professores alfabetizadores na esfera federal, que abarca em suas ações o eixo da avaliação. A avaliação é o terceiro eixo do PNAIC, cujo objetivo pretende produzir indicadores que contribuam para o processo de alfabetização nas escolas brasileiras.

Nesse sentido, optou-se por analisar os resultados obtidos na ANA, no Munícipio de Ponta Grossa, no teste de leitura, a fim de verificar as possibilidades de comparabilidade dos resultados para construir um diagnóstico referente à formação do aluno leitor.

Os resultados referentes à leitura no Brasil, na última edição da ANA, em 2016, conforme Relatório do MEC (INEP, 2018), indicam que 21 ,74\% das crianças brasileiras estão no nível 1; 32,99\% no nível 2; 32,28\% no nível 3 e 12,99\% no nível 4. No Paraná, os índices marcam: 9,92\% no nível 1; 34,81\% no nível 2; 40,37\% no nível 3 e 14,9\% no nível 4.

No Município de Ponta Grossa, considerando as três edições da ANA, realizadas nos anos de 2013, 2014 e 2016, das 83 escolas do município foram disponibilizados, no Painel Educacional do INEP, os resultados de 72 escolas no teste de proficiência em Leitura. A justificativa para a inexistência do resultado de algumas escolas é pelo fato de haver menos de 10 alunos matriculados no $3^{\circ}$ ano.

Os resultados gerais ficaram assim distribuídos: 
Tabela 3- Distribuição percentual dos estudantes por nível de proficiência em leitura - Ponta Grossa/Paraná

\begin{tabular}{|c|c|c|c|}
\hline Nível & 2013 & 2014 & 2016 \\
\hline Nível I (Até 425 pontos) & $20,99 \%$ & $21,49 \%$ & $17,24 \%$ \\
\hline Nível 2 (Maior que 425 até 525 pontos) & $33,06 \%$ & $36,42 \%$ & $32,46 \%$ \\
\hline Nível 4 (Maior que 525 até 625 pontos) & $35,23 \%$ & $34,00 \%$ & $38,24 \%$ \\
\hline & $10,73 \%$ & $8,10 \%$ & $12,06 \%$ \\
\hline
\end{tabular}

Fonte: Elaboração da autora, INEP (2016).

Comparativamente, os resultados indicam um aumento no nível de leitura; quanto menor o nível I tanto melhor serão os demais níveis, demostrando que os alunos avançaram do nível da decodificação para a compreensão do texto.

Observa-se pela leitura da tabela 3, que entre os anos de 2014 e 2016, houve queda do nível I, de $21,49 \%$ para 17,24\%. Leve queda no nível 2, de 36,42\% para 32,46\%, significando que quanto menor o índice de leitura nestes níveis, melhor estão os níveis que exigem maior esforço do leitor. No nível 3 , destes mesmos anos, houve elevação de 34\% para 38,24\% e no nível 4, elevação de 8, 10\% para 12,06\% aumentando o nível de leitura dos alunos.

A maioria dos alunos concentra-se nos níveis 2 e 3, ou seja, conseguem ler as ideias explícitas, recuperar os sentidos do texto, por meio das relações que se fazem entre o leitor- texto-autor. Conseguem levantar hipóteses de leitura, inferem ideias implícitas e estabelecem relações de sentidos utilizando o conhecimento linguístico acerca dos elementos referenciais.

O levantamento dos resultados das 72 escolas da rede municipal, nas três edições do teste de leitura, distribuídas entre escolas urbanas e rurais, com nível do INSE entre médio e médio alto, como também os indicadores da formação docente permitiram estabelecer os seguintes critérios de análise:
A- Escolas cujos índices de formação e leitura aumentaram;
B- Escolas cujos índices de formação e leitura diminuíram;
C- Escolas cujos índices de formação diminuíram e os índices de leitura aumentaram;
D- Escolas cujos índices de formação aumentaram e os índices de leitura diminuíram.

Tabela 4 - Critérios para análise das escolas a partir da relação formação docente e proficiência em leitura

\begin{tabular}{|l|c|c|}
\hline \multicolumn{1}{|c|}{ CRITÉRIOS } & $\begin{array}{c}\text { NÚMERO DE } \\
\text { ESCOLAS }\end{array}$ & PERCENTUAL \\
\hline $\begin{array}{l}\text { A- Escolas cujos índices de formação docente e } \\
\text { proficiência em leitura aumentaram }\end{array}$ & 33 & $45,8 \%$ \\
\hline $\begin{array}{l}\text { B- Escolas cujos índices de formação docente e } \\
\text { proficiência em leitura diminuíram }\end{array}$ & 15 & $20,8 \%$ \\
\hline $\begin{array}{l}\text { C- Escolas cujos índices de formação docente } \\
\text { diminuíram e os índices de proficiência em leitura } \\
\text { aumentaram }\end{array}$ & 17 & $23,6 \%$ \\
\hline $\begin{array}{l}\text { D- Escolas cujos índices de formação docente } \\
\text { aumentaram e os índices de proficiência em } \\
\text { leitura diminuíram }\end{array}$ & 07 & $9,8 \%$ \\
\hline \multicolumn{1}{|c|}{ Total } & 72 & $100 \%$ \\
\hline
\end{tabular}

Fonte: Elaboração da autora. INEP ( 20|6). 
Na sequência, serão apresentados e discutidos os resultados do teste em leitura. Para uma análise mais detalhada, foram escolhidas quatro escolas com resultados mais significativos para compor a amostra em cada critério

As escolas cujos índices de formação docente e proficiência em leitura aumentaram detiveram o maior percentual observado 45,8\%, dentre estas escolas destaca-se a escola A:

Tabela 5- Níveis de proficiência em leitura e formação docente da escola A.

\begin{tabular}{|c|c|c|c|}
\hline NívelS & 2013 & 2014 & 2016 \\
\hline Nível I & $32,97 \%$ & $19,61 \%$ & $9,38 \%$ \\
\hline Nível 2 & $17,84 \%$ & $31,37 \%$ & $21,88 \%$ \\
\hline Nível 3 & $36,49 \%$ & $41,18 \%$ & $40,63 \%$ \\
\hline Nível 4 & $12,7 \%$ & $7,84 \%$ & $28,13 \%$ \\
\hline FORMAÇÃO DOCENTE & $75 \%$ & $92,8 \%$ & $93,2 \%$ \\
\hline
\end{tabular}

Fonte: Elaboração da autora. INEP ( $20 \mid 6)$.

Pela leitura da tabela acima, verifica-se que, proporcionalmente, o nível I, que indicava 32,97\% em 2013 , diminuiu para 19,61\% e 9,38\%, respectivamente, apontando que os alunos avançaram no nível de leitura.

O nível 2 apresentou uma elevação de 17,84\% para 31,37\% aumententando o percentual desse nível entre os anos 2013 e 2014, porém, em 2016, esse nível regrediu em média 10 pontos percentuais: $21,88 \%$, indicando o avanço da aprendizagem dos conhecimentos explícitos para níveis mais elaborados de leitura.

A maioria dos alunos concentra-se no nível 3, entre os anos de 2013, 2014 e 2016 atingiu os índices de 36,49\%, 4I, I 8\% e 40,63\% respectivamente. E, no nível 4, observou-se que houve queda de $5 \%$ entre os anos de 2013 e 2014 , contudo, houve um avanço para 28, I3\% no ano de 2016 , apontando que os alunos já conseguiam inferir ideias implícitas, estabelecendo relações de sentidos, compreendendo "[...] como os elementos linguísticos presentes na superfície textual se encontram interligados, por meio de recursos também linguísticos, formando sequências veiculadoras de sentido" (KOCH; ELIAS, 2008, p. 35).

Quanto à formação docente, observou-se um aumento considerável entre os anos de 2013 e 2014 , de $75 \%$ passou para $92,8 \%$ e para o ano de 2016 , o índice de formação se manteve em 93,2\%. Esse aumento refletiu na queda do nível I, de 32,97\% para 9,38\% na $3^{\text {a }}$ edição da ANA e paralelamente, no nível 4, último nível da escala de proficiência, um aumento de 12,7\% para 28, 13\%, indicando que à medida que aumenta o índice de formação, por meio de cursos de capacitação como o PNAIC, em que o professor participa de cursos sobre leitura na área da alfabetização, esse conhecimento 
configura-se como elemento primordial para subsidiar práticas significativas e, consequentemente, avançar no nível de leitura dos alunos corroborando com a formação do leitor.

É relevante salientar o papel do professor como mediador de leituras para contribuir na formação de leitores ativos e críticos, é fundamental que a ação seja planejada com foco no que os alunos podem aprender para ampliar seus horizontes culturais e agir na sociedade de modo crítico, pois, ao ensinar a ler, ensinam-se os conteúdos tratados nos textos que são lidos (BRASIL, 20 I 5).

As escolas cujos índices de formação docente e proficiência em leitura diminuíram somam 20,8\%, dentre estas escolas verificou-se os índices da escola B:

Tabela 6 - Níveis de proficiência em leitura e formação docente da escola B

\begin{tabular}{|c|c|c|c|}
\hline NÍvEIS & 2013 & 2014 & 2016 \\
\hline Nível I & $28,57 \%$ & $8,33 \%$ & $37,5 \%$ \\
\hline Nível 2 & $28,57 \%$ & $16,67 \%$ & $31,52 \%$ \\
\hline Nível 3 & $28,57 \%$ & $66,37 \%$ & $31,25 \%$ \\
\hline Nível 4 & $14,29 \%$ & $8,33 \%$ & $0,0 \%$ \\
\hline FORMAÇÃO DOCENTE & $66,67 \%$ & $70 \%$ & $60,6 \%$ \\
\hline
\end{tabular}

Fonte: Elaboração da autora. INEP ( 20|6).

A tabela acima explicita a realidade da escola podendo-se observar que entre os anos de 2013 e $20 \mid 4$ houve uma queda nos níveis I e 2 de leitura de 28, 57\% para 8,33\% e 28,57\% para $16,67 \%$ e aumento considerável no nível 3 de 28,57\% para 66,37\%, tais dados demonstram que a escola vinha desenvolvendo ações significativas no eixo da leitura, apenas, no nível 4, cujo nível exige maior conhecimento relacionado à interpretação ao processo de inferências e implícitos, os alunos ainda não avançaram.

É mister mencionar que a formação docente, nestes anos, teve um aumento de aproximadamente 4 pontos, contudo, pelo critério da rotatividade dos docentes, apresentado no gráfico 5 da primeira categoria, cujos índices apontam para 67\% de permanência em torno de 2,5 anos, a escola não manteve o mesmo corpo docente em 2016 , pois, a formação apresentou um decréscimo de 10 pontos: 60,6\%.

Esse índice apontou consequências expressivas no baixo rendimento dos alunos em 2016, o nível I foi o índice mais significativo, de 8,33\% elevou-se para 37,5\%, ou seja, 29 pontos de percentual indicam que os alunos apenas conseguiam identificar palavras com diferentes quantidades de sílabas e estruturas silábicas relacionando a palavra à imagem. Para o nível 2, em que os alunos conseguem identificar ideias explícitas no texto, onde tudo já está dito, houve um aumento de 16,67\% para 31,52\%.

O nível 3 - que em 2014 tinha sido destaque com 66, 37\% - caiu para 31,25\%, ou seja, mais de 35 pontos percentuais, e, para o nível 4, não houve índice de rendimento. Os níveis I e 2 precisam manter-se em escala menor na proporção aos níveis 3 e 4, indicando o avanço na compreensão leitora, 
entretanto, em 20,8\% das escolas de Ponta Grossa, esse quadro é indicativo da necessidade de ações concretas para a construção do aluno leitor.

Cruz e Martiniak (2018, p. 76) destacam que:

[...] as avaliações externas têm demonstrado, em altos índices, o precário desempenho dos alunos em provas de leitura, escrita e interpretação de textos, denunciando a existência de contingentes de alunos não alfabetizados ou semialfabetizados.

As avaliações confirmam a ideia de que as dificuldades estão relacionadas à necessidade do domínio da leitura, porém, "[...] diante dos resultados e dos interesses impostos pelo capital, várias estratégias e recursos são demandados para amenizar e solucionar os problemas educacionais e melhorar a qualidade da aprendizagem" (CRUZ; MARTINIAK, 20I8, p. 77)

Estado tem promovido cursos de formação continuada e em serviço aos professores alfabetizadores, porém, todos esses artifícios são formas de

[...] correr-se atrás do prejuízo de uma formação ineficiente que se plantou no país nas três últimas décadas; é a colheita de investimentos ruins, ou melhor, da falta de investimentos sérios na educação brasileira. (SHIMAZAKI; MENEGASSI, 2016, p. 20I)

Muitas vezes, a culpa pelo baixo rendimento dos alunos é imposta ao professor e à escola, atribuindo a estes o desconhecimento do que significa ler, comprender, interpretar pelo fato de trabalhar com estruturas linguísticas fracionadas e descontextualizadas, indicando a falta de clareza e objetividade ao tratar dos conceitos de alfabetização e letramento.

Entretanto, à escola cabe a função de proporcionar à criança os direitos da aprendizagem e o acesso ao mundo letrado. $O$ trabalho do professor alfabetizador deve estar pautado por este princípio, considerando os condicionantes históricos, políticos e sociais, sua ação docente deve privilegiar práticas escolares significativas que subsidiem a formação de alunos leitores não só da palavra, mas no conhecimento de compreender, interpretar, argumentar fazendo uso da leitura em suas práticas sociais.

A seguir, as escolas cujos índices de formação docente diminuíram e os índices de proficiência em leitura aumentaram somam 23,6\%, dentre estas escolas encontra-se a escola C:

Tabela 7- Níveis de proficiência em leitura e formação docente da escola $C$

\begin{tabular}{|c|c|c|c|}
\hline NívEIS & 2013 & 2014 & 2016 \\
\hline Nível I & $29,06 \%$ & $18,97 \%$ & $4,0 \%$ \\
\hline Nível 2 & $24,27 \%$ & $32,76 \%$ & $28,0 \%$ \\
\hline Nível 3 & $34,38 \%$ & $46,55 \%$ & $48,0 \%$ \\
\hline Nível 4 & $12,29 \%$ & $1,72 \%$ & $20,0 \%$ \\
\hline FORMAÇÃO DOCENTE & $75 \%$ & $75 \%$ & $47 \%$ \\
\hline
\end{tabular}

Fonte: Elaboração da autora. INEP ( 2016$)$. 
Os dados indicados na tabela 7 revelaram que gradativamente os estudantes foram elevando o índice de leitura, entretanto, na formação docente este diagnóstico não foi confirmado, ao contrário, nos dois primeiros anos se manteve e no terceiro ano da aplicação da ANA decaiu em 28 pontos percentuais.

Entre os anos de 2013 e 2014, o nível I, variou de 29,06\% para 18,97\% e, em 2016, atingiu o índice de 4\%, ou seja, muitos alunos avançaram no processo de decodificação para a compreensão leitora. Para o nível 2, o índice marcava 24,27\% em 2013, passou para 32,76\% em 20 I4, e registrou 28\% em 2016.

Já no nível 3, os alunos apresentaram um aumento que variou entre 34,29\%, 46,55\% e 48\%; no nível 4, o índice iniciou em 12,29\%, caiu para 1,72\% e elevou-se para 20\%. À medida que os níveis I e 2 apresentaram declínio observou-se uma elevação do nível 3, e, apesar de apresentar queda em 20 |4, o nível atingiu o índice de 20\% em 2016.

Tais índices revelaram a apropriação do conhecimento para ler textos em que as ideias estavam implícitas, nas entrelinhas do texto, no uso da linguagem figurada, para relacionar com as informações do seu cotidiano, desenvolvendo um aluno leitor para além do está expresso na materialidade dos textos.

Apesar de os índices da formação docente indicarem uma diminuição de 28 pontos percentuais, verificou-se que o conhecimento dos alunos que caminhavam para um processo de elevação manteve-se em contínuo crescimento até porque nos anos de 2013 e 2014 a formação docente marcava o índice de $75 \%$.

Neste critério foram 23,6\% o índice de escolas em que a formação docente diminui, porém o rendimento dos alunos aumentou. Um indicativo para este percentual está relacionado com a rotatividade dos professores na escola não necessariamente troca de professor dos alunos que realizaram o teste haja vista os resultados alcançados.

Fatores como a satisfação e o engajamento ativo da comunidade escolar e, sobretudo, das crianças e do professor no processo de ensino e aprendizagem são essenciais na construção e desenvolvimento de alunos mais participativos e ativos, segundo Saviani (2004), é tão necessário analisar as políticas para a alfabetização quanto à formação dos professores alfabetizadores.

Nessa perspectiva, é preciso pensar as relações estabelecidas por meio do trabalho - da ação docente - na sociedade capitalista, destacando as deficiências do saber produzido por uma formação fragmentada e aligeirada, sem aprofundamento sobre o conhecimento científico, uma prática sem reflexão e atenção especial para as questões de burocratização do ensino.

E, finalmente, as escolas cujos índices de formação docente aumentaram e os índices de proficiência em leitura diminuíram somam 9,8\%, entre elas observa-se a escola D: 
Tabela 8 - Níveis de proficiência em leitura e formação docente da escola $D$

\begin{tabular}{|c|c|c|c|}
\hline NÍvEIS & 2013 & 2014 & 2016 \\
\hline Nível I & $9,09 \%$ & $6,0 \%$ & $23,08 \%$ \\
\hline Nível 2 & $45,43 \%$ & $40,0 \%$ & $26,92 \%$ \\
\hline Nível 3 & $36,34 \%$ & $40,0 \%$ & $38,46 \%$ \\
\hline Nível 4 & $9,13 \%$ & $14,0 \%$ & $11,54 \%$ \\
\hline FORMAÇÃO DOCENTE & $50 \%$ & $44 \%$ & $62,5 \%$ \\
\hline
\end{tabular}

Fonte: Elaboração da autora. INEP ( 20|6).

Observa-se por meio da tabela 8 , embora em menor quantidade, apenas $9,8 \%$ das escolas em Ponta Grossa, PR, que a formação docente aumentou e os índices de leitura ainda oscilam com maior incidência no nível I.

Entre os anos de 2013 e 2014, o nível I caiu em 3 pontos percentuais, mas em 20 I6, esse índice elevou para $23,08 \%$ quando a formação docente indicava $50 \%$, depois $44,6 \%$ e aumentou para $62,5 \%$ em 2016.

O mesmo não acontece no nível 2, que vai diminuindo, em 2013 marcava 45,43\%, em 20।4, 40\% e, em 2016, há uma queda para 26,92\%. Já o nível 3, houve pequenas oscilações entre 36,34\%, 40\% e 38,46\%. No nível 4, o índice apontava em 2013 para 9,13\%, no ano seguinte para 14\%, elevando em aproximadamente 5 pontos percentuais e no último ano da aplicação do teste uma queda para | I,54\%.

Pela análise dos índices foi possível verificar que apenas a elevação dos níveis de formação docente não garante necessariamente a compreensão leitora dos alunos. É preciso investir na formação do leitor, orientar o processo com a utilização de variadas estratégias de leitura.

A leitura na escola deve ultrapassar a decodificação, $1^{\circ}$ nível de leitura, cuja ênfase refere-se aos treinos de fonemas, sílabas ou palavras, a atenção volta-se para a decifração das palavras, sem direcionar a leitura à busca de construir sentido na interação com textos. A mediação deve ser orientada no sentido de aprender que o sentido do texto "não é uma decorrência automática da identificação de grafemas e de suas correspondências sonoras" (BRASIL, 20I5, p. 32).

Os alunos progridem a partir de uma leitura compreensiva - entendida como a leitura que se limita a explorar os elementos internos do enunciado, os sentidos denotados - ao enriquecimento da leitura interpretativa - entendida como a leitura que utiliza conhecimentos externos para suscitar significados implícitos, outros sentidos que emergem dos textos (COLOMER; CAMPS, 2002). 


\section{CONSIDERAÇÕES FINAIS}

Este estudo teve como questão problematizadora a análise das políticas públicas educacionais em âmbito federal, a fim de verificação da influência destas políticas de formação continuada de professores alfabetizadores nos efeitos da formação do aluno leitor, por meio dos resultados alcançados na Avaliação Nacional de Alfabetização - ANA, no eixo da leitura.

No geral, verificou-se que $45,8 \%$ das escolas no critério A e $9,8 \%$ no critério D, aumentaram o nível da formação docente, somando 55,6\%. Nos critérios B e C, somam 20,8\% e 23,6\%, ou seja, 44,4\% das escolas não mantiveram os índices, esses resultados confirmam que, embora em menor proporção, há lacunas e fragilidades na formação docente, trata-se de uma formação inicial e continuada que desconsidera o conhecimento teórico em detrimento do conhecimento técnico-prático.

Considera-se, assim, as condições sociais em que tal formação possa ocorrer, o trabalho pedagógico deve estar pautado pelo acesso aos direitos da aprendizagem. Aos professores alfabetizadores cabe a atuação considerando os condicionantes históricos, políticos e sociais, contudo, alicerçando a ação docente em práticas escolares significativas a este cenário de complexas relações de poder.

A formação continuada ocorre a partir da prática, nas vivências do dia a dia, na rotina, nas atribulações da profissão, de forma aligeirada, fragmentada, um conhecimento tácito pelas demandas de resultados satisfatórios, visando ao cumprimento de contingente para suprir as demandas do mercado capital, que certifica como exigência de metas e fins estabelecidos pela competitividade.

Ademais, exige-se do professor alfabetizador planejamento diferenciado, pois, há alunos com conhecimentos, dificuldades e necessidades variadas. Destarte, é urgente conceber a formação de professores sob o viés que prepara criticamente com o objetivo de desenvolver no ser humano as condições para atuar no sentido da superação dos limites, da alienação das consciências produzidas pelas relações existentes na sociedade capitalista, em que o lucro e as estatísticas comandam muitas ações na educação.

Não se pode afirmar que os resultados da ANA, especificamente de leitura, cujos índices nos critérios A e C apontaram para um aumento do nível de leitura em 69,4\% em contraposição aos índices que indicaram uma diminuição do nível de leitura em 30,06\% nos critérios B e D alcançando a diferença de 39,34 pontos percentuais, estejam atrelados aos cursos de capacitação aos docentes oferecidos pelo PNAIC, ao contrário, são muitos fatores que influenciam o desenvolvimento de potencialidades no eixo da leitura.

Os resultados, portanto, indicam as contradições, limites e perspectivas em relação aos índices alcançados: o resultado final emana de muitos fatores circunstânciais: 
- da ação docente como mediação do processo, do nível de entendimento e aplicação de práticas significativas de leitura em sala de aula, de estratégias pontuais em todos os níveis de leitura, desde a decifração até as relações internas do texto, para propiciar o domínio da compreensão leitora dos alunos;

- do nível socioeconômico não retratar a realidade das famílias dos alunos, pais e mães que são leitores podem facilitar o convívio ao mundo letrado, mas em um contexto notadamente marcado pela crise econômica, onde faltam os recursos básicos a leitura fica designada à escola;

- do teste de leitura ser único para o Brasil, assim são desconsideradas regionalidades, diferenças sociais, faixa etária dos alunos, bem como o plano de trabalho docente das Secretarias de Educação, todos são fatores contextuais que implicam o resultado final.

As avaliações externas, como a ANA, têm o objetivo de medir o rendimento dos alunos e não avaliar o sistema como um todo, pois faltam mecanismos que permitam comparar longitudinalmente os resultados obtidos para analisar as possíveis mudanças que se operam a partir das políticas e programas implementados.

A preocupação está nos resultados das provas, na sua dimensão técnica, não se enfatizam as análises contextuais que permitem um melhor entendimento da situação educacional e uma intervenção mais efetiva.

Não se trata de responsabilizar o professor e a escola pelos resultados obtidos, estes devem servir como diagnóstico da realidade para ratificar a necessidade de que as políticas públicas educacionais promovam uma formação sólida, fundamentada pelas teorias do conhecimento considerando as práticas sociais para ampliar a compreensão leitora.

Os resultados desta pesquisa indicaram que houve mudanças na formação do leitor, mas não se pode comprovar que os índices tiveram elevação em decorrência apenas da formação continuada dos professores alfabetizadores por meio de sua participação nos cursos de formação do PNAIC, justamente porque o contexto das escolas contempla um processo construído por muitos condicionantes.

Em relação ao instrumento de leitura, os resultados mostraram a compreensão de leitura em um determinado nível medido pela coletividade dos alunos, entretanto, este índice não significa que o aluno não tenha condições de resolver questões de nível mais elaborado, haja vista que os resultados são calculados pela Teoria de Resposta ao Item (TRI) demonstrando dados quantitativos da escola. É necessário, porém, buscar mecanismos para identificar dificuldades pontuais dos alunos, minimizando-as e avançando no processo de formação do aluno leitor.

No que se refere à construção do aluno leitor, verificou-se que 69,4\% dos alunos vêm demonstrando crescimento na aprendizagem da leitura, contudo, a formação do leitor crítico ainda carece de mais ações pontuais para o desenvolvimento da leitura crítica, da compreensão das relações contextuais, 
dos implícitos e subentendidos e estes conhecimentos ocorrem ao longo da formação escolar e se estendem para a vida fora da escola, pois 30,06\% ainda apresentam níveis insuficientes de leitura.

Formar alunos críticos, participativos requer desenvolver a autonomia para realizarem-se como cidadãos capazes de respeitar direitos, cumprir deveres, reivindicar melhorias, preservar e difundir cultura, enfim, serem protagonistas de suas próprias histórias.

Em relação à formação continuada de professores alfabetizadores, os dados revelaram um índice de 55,6\% de aumento no nível de formação no Município de Ponta Grossa, porém, não se pode vincular este índice ao fato de os professores participarem dos cursos de formação continuada do PNAIC, pois a adesão dos professores alfabetizadores não aconteceu de forma progressiva e contínua.

Os conhecimentos teórico-metodológicos sobre leitura nos programas de formação continuada de professores alfabetizadores, foram importantes para subsidiar a prática pedagógica, todavia, não se pode nivelar o processo de construção do aluno leitor pelos resultados oriundos de um programa federal como o PNAIC, porque as escolas apresentam realidades distintas, contextos culturais, sociais e econômicos específicos, alunos singulares com características diversas e professores com experiências distintas.

Esses fatores não têm sido considerados pela política de avaliação em larga escala que produz dados pautados em testes relativizados para cumprir com a ação determinada pelo eixo da avaliação, entretanto é necessário que as políticas públicas não apenas sirvam para remediar o problema do analfabetismo de crianças brasileiras.

Portanto, analisar a formação continuada de professores alfabetizadores como garantia de educação significativa é condição imprescindível para a igualdade de oportunidades para todos os cidadãos. É peça fundamental para o agir na história da vida dos alunos, auxiliando-os na compreensão da leitura como forma de conhecimento, do entendimento das relações dos textos com o mundo, dos enunciados explícitos e implícitos, da análise, da reflexão e da busca pela construção deste leitor.

\section{REFERÊNCIAS}

BRASIL. Decreto n 6094, de 24 de abril de 2007. Dispõe sobre a implementação do Plano de Metas Compromisso Todos pela Educação, pela União Federal, em regime de colaboração com Municípios, Distrito Federal e Estados, e a participação das famílias e comunidade, mediante programas e ações de assistência técnica e financeira, visando a mobilização social pela melhoria da qualidade da educação básica. Diário Oficial da União. Brasília, DF, no79, p. 5-6, 25 abr. 2007.

BRASIL. Portaria no 867, de 4 de julho de 2012. Institui o Pacto Nacional pela Alfabetização na Idade Certa e as ações do Pacto e define suas diretrizes gerais. Diário Oficial da União. Brasília, 5 jul. 20 I $2 a$.

BRASIL. Ministério da Educação. Secretaria de Educação Básica. SISPACTO. Brasília: MEC/ SEB, 2013. 
BRASIL. MEC/INEP. Ministério da Educação. Instituto Nacional de Estudos e Pesquisas Educacionais Anísio Teixeira. Resumo técnico do Censo da Educação Básica. Brasília, 2013.

BRASIL. Secretaria de Educação Básica. Diretoria de Apoio à Gestão Educacional. Pacto nacional pela alfabetização na idade certa: Caderno 5/ Ministério da Educação, Secretaria de Educação Básica, Diretoria de Apoio à Gestão Educacional. - Brasília: MEC, SEB, 2015.

BRASIL. INEP. Avaliação Nacional da Alfabetização: relatório 20 I3-20 I4: volume I: da concepção à realização. - Brasília, DF: INEP, 20I5. II 5 p.

BRASIL. INEP. Avaliação Nacional da Alfabetização: relatório 2013-20।4: volume 2: análise dos resultados. - Brasília, DF: INEP, 20I5. 120 p.

BRASIL. INEP. Boletim escolar. 20 16. Disponível em: http://ana.inep.gov.br/ANA/>.

BRASIL. INEP. Relatório SAEB/ANA 2016: panorama do Brasil e dos estados. - Brasília, DF: INEP, 2018. $235 \mathrm{p}$.

CAGLIARI, Luiz Carlos. Alfabetização e Linguística. 10. ed. São Paulo: Scipione, 1997. 191 p.

COLOMER, Teresa; CAMPS, Anna. Ensinar a ler, ensinar a compreender. Tradução de Fátima Murad. I. ed. Porto Alegre: Artmed, 2002.

CRUZ, Eliane Travensoli Parise; MARTINIAK, Vera Lucia. $O$ ensino da leitura e sua relação com a formação de alfabetizadores: apontamentos a partir da produção acadêmica. Práxis Educativa, [S.L.], v. 13, n. I, p. 67-84, 20 18. Universidade Estadual de Ponta Grossa (UEPG). http://dx.doi.org/l0.5212/praxeduc.v. I 3il .0004.

DUARTE, Newton. Vigotski e o "aprender a aprender": crítica às apropriações neoliberais e pósmodernas da teoria vigotskiana. 2. ed. Campinas: Autores Associados, 200 I . 297 p.

FREITAS, Luiz Carlos. Cenário educacional: o legado dos anos 80 e a confusão dos anos 90. E agora? In: SIMPÓSIO DO LAGE, 3., 2000, Jundiaí. Anais... Jundiaí, 2000.

GERALDI, João Wanderley. Prefácio. In: GONTIJO, Claudia Maria Mendes. Alfabetização: políticas mundiais e movimentos nacionais. Campinas, SP: Autores Associados, 2014. 160 p.

$\mathrm{KOCH}$, Ingedore Villaça; ELIAS, Vanda Maria (org.). Ler e compreender os sentidos do texto. 3. ed. São Paulo: Contexto, 2008. 216 p.

SAVIANI, Dermeval. Educação no Brasil: concepção e desafios para o século XXI. Revista HISTEDBR on-line, Campinas, n. 3, jul. 2001.

SHIMAZAKI, Elsa Midori; MENEGASSI, Renilson José. O formador de professores de Língua Portuguesa do PNAIC e as alterações em suas práticas profissionais. Práxis Educativa, [S.L.], v. II, n. I , p. 199-2 I3, 20 I 5. Universidade Estadual de Ponta Grossa (UEPG). http://dx.doi.org/I0.52 I2/praxeduc.v. I lil.0009. 


\section{COMO CITAR ESSE ARTIGO}

\section{Associação Brasileira de Normas Técnicas (ABNT)}

CRUZ, Eliane Travensoli Parise; MARTINIAK, Vera Lucia. Leitura e formação docente: implicações para a construção do aluno leitor. Debates em Educação, Maceió, v. I2, p. I54- I7I, set. 2020. ISSN 2175 6600. Disponível em: https://www.seer.ufal.br/index.php/debateseducacao/article/view/9953. Acesso em: dd mmm. aaaa.

\section{American Psychological Association (APA)}

Cruz, E., \& Martiniak, V. (2020). Leitura e formação docente: implicações para a construção do aluno leitor. Debates em Educação, I2(Esp), I54-I7l. doi: https://doi.org/l0.28998/21756600.2020v I 2nEspp I 54- I7I 